\title{
Effect of optimal glycaemic control with continuous subcutaneous insulin infusion on energy expenditure in type I diabetes mellitus
}

\author{
P LESLIE， R T JUNG， T E ISLES， J BATY， R W NEWTON， P ILLINGWORTH
}

\begin{abstract}
To assess the role of insulin in the control of body weight energy expenditure was measured by indirect calorimetry in eight patients of normal weight with type I diabetes initially while poorly controlled during conventional insulin treatment and later during optimal glycaemic control achieved by using the continuous subcutaneous insulin infusion pump. Their response to seven days of fat supplementation was also assessed and the results compared with those in eight non-diabetic subjects. After a mean of 5.3 months of continuous subcutaneous insulin infusion the diabetic subjects had gained on average $3.5 \mathrm{~kg}$. In the poorly controlled diabetic state the resting metabolic rate was raised but decreased by a mean of $374 \mathrm{~kJ}(90 \mathrm{kcal})$ per 24 hours with optimal glycaemic control. The thermic response to infused noradrenaline was reduced by $\mathbf{5 9 \%}$ in the diabetic subjects, was not improved by continuous subcutaneous insulin infusion, but was improved when three of the subjects were given metformin in addition. The diabetic subjects had no abnormality in the thermic response to a meal while taking their usual diabetic diet. During fat supplementation, however, this thermic response was reduced when glycaemic control was poor but not when control was precise. Fat supplementation did not alter the resting metabolic rate or the reduced noradrenergic thermic response in the diabetic subjects.

These findings suggest that precise glycaemic control could produce weight gain if energy intake remained unaltered, for diabetic subjects do not compensate for the decrease in metabolic rate by an increase in noradrenergic and dietary thermic responses. Also precise glycaemic control using continuous subcutaneous insulin infusion does not correct all the metabolic abnormalities of diabetes mellitus.
\end{abstract}

Ninewells Hospital and Medical School, Dundee DD1 9SY

P LESLIE, BSC, MRCP, research fellow, department of medicine

R T JUNG, MD, FRCPED, consultant physician, department of medicine

T E ISLES, BSC, PHD, senior lecturer in biochemical medicine

J BATY, BSC, medical laboratory scientific officer, department of biochemical medicine

R W NEWTON, MB, FRCPED, consultant physician, department of medicine PILLINGWORTH, MB, CHB, research fellow, department of gynaecology

Correspondence to: Dr Jung

\section{Introduction}

Maintaining an acceptable weight may pose considerable difficulties in the management of patients with insulin dependent diabetes. Animal studies suggest that insulin may play an important part in modulating energy expenditure. ${ }^{12}$ In cafeteria overfed rats insulin is necessary for excess energy to be expended by the stimulation of non-shivering thermogenesis. ${ }^{1} \mathrm{~A}$ reduced thermic response to a glucose drink has been reported in some obese non-diabetic and obese type II diabetic subjects. ${ }^{3}$ This abnormality may be reversed by using a euglycaemic insulin clamp technique, suggesting that insulin resistance may be implicated. ${ }^{+}$In clinical practice, however, it is usually a gain in weight and not loss of weight which is seen when glycaemic control is improved by adequate insulin repletion in patients with type I diabetes. ${ }^{5}$ To study this further we have investigated the role of insulin in modulating energy expenditure in insulin dependent (type I) diabetic subjects of normal weight, initially while poorly controlled during conventional insulin treatment and then when optimal glycaemic control was achieved using continuous subcutaneous insulin infusion. As it is likely that diabetic patients gain weight by overeating mainly fat, we have examined the adaptive responses of our diabetic subjects when their diet was supplemented with extra fat during both poor and optimal glycaemic control. The diabetic responses were compared with those of eight non-diabetic volunteers of normal weight.

\section{Subjects and methods}

We studied eight insulin dependent diabetic subjects taking conventional twice daily short and intermediate acting insulin regimens and eight nondiabetic subjects of similar age and weight (see table I). The diabetic subjects were recruited from our diabetic clinic at Ninewells Hospital and were chosen for their poor control with conventional treatment and their willingness to be treated by continuous subcutaneous insulin infusion. Each volunteered with full knowledge that this was to be a research study. The number of diabetic subjects recruited was determined by the number of insulin pumps available. The duration of diabetes ranged from four months to 16 years with an average duration of 6.8 years. Fasting $C$ peptide concentrations (Novo Research Institute radioimmunoassay kit DK-2880, Bagbaerd, Denmark) were undetectable in three subjects, $0.03 \mathrm{nmol} / 1 \mathrm{in}$ two, $0.04 \mathrm{nmol} / 1$ in two, and $0.14 \mathrm{nmol} / 1$ in one (normal fasting reference range $0 \cdot 18-0 \cdot 63 \mathrm{nmol} / \mathrm{l}$ ). The non-diabetic subjects were recruited from hospital staff and the community. All the subjects were biochemically 
euthyroid and none was obese as defined by a body mass index of greater than 27 . Ideal body weight was defined as that given as an acceptable average weight in the report of the Royal College of Physicians ${ }^{6}$ based on the weight for height tables of the Metropolitan Life Insurance Company.

Diabetic subjects were studied initially during poor metabolic control with conventional treatment and later during optimal glycaemic control achieved by continuous subcutaneous insulin infusion using a Travenol AS6C-U100 pump. The mean period between the studies of energy expenditure during conventional treatment and with continuous subcutaneous insulin infusion was $5 \cdot 3$ months (range $3 \cdot 5-7 \cdot 0$ months).

TABLE I-Details of subjects. (Mean values expressed with SD in parentheses)

\begin{tabular}{|c|c|c|c|c|c|c|}
\hline $\begin{array}{l}\text { Study } \\
\text { group }\end{array}$ & $\begin{array}{c}\text { Sex } \\
(\mathbf{F}: \mathbf{M})\end{array}$ & $\begin{array}{c}\text { Age } \\
\text { (years) }\end{array}$ & $\begin{array}{c}\text { Weight } \\
(\mathrm{kg})\end{array}$ & $\begin{array}{c}\text { Body mass } \\
\text { index }(\text { weight } \\
\left.\text { height }{ }^{2}\right)\end{array}$ & $\begin{array}{c}\text { Energy } \\
\text { content of test } \\
\text { meal }(\mathrm{MJ})\end{array}$ & $\begin{array}{c}\text { Noradrenaline } \\
\text { infusion } \\
(\mu \mathrm{g} / \mathrm{min})\end{array}$ \\
\hline $\begin{array}{l}\text { Non-diabetics } \\
(\mathrm{n}=8) \\
\text { Diabetics }\end{array}$ & $6: 2$ & $26 \cdot 3(3 \cdot 4)$ & $59 \cdot 8 \quad(4 \cdot 8)$ & $21 \cdot 7(1 \cdot 7)$ & $1.97(0.16)$ & $6 \cdot 10(0 \cdot 72)$ \\
\hline$(\mathrm{n}=8)$ & $6: 2$ & $31 \cdot 1(8 \cdot 1)$ & $67 \cdot 9(12 \cdot 0)$ & $24 \cdot 2(2 \cdot 8)$ & $1.80(0.13)$ & $5.97(0.75)^{\star}$ \\
\hline
\end{tabular}

* Seven diabetics only

Conversion: SI to traditional units-Energy: $1 \mathrm{MJ} \approx 240 \mathrm{kcal}$.

\section{PROCEDURE}

Energy expenditure was measured using an indirect ventilated hood calorimeter. Oxygen consumption and carbon dioxide production were measured by paramagnetic (Taylor, Servomex) and infrared (SS-200, Analytic Development Co Ltd) analysis respectively. Energy expenditure was calculated from the formula of Weir and expressed in $\mathrm{kJ} / \mathrm{min} .^{8}$ All measurements were performed after a 12 hour overnight fast with the subjects resting semirecumbent in a thermoneutral $\left(25-27^{\circ} \mathrm{C}\right)$ environment. In order to prevent fasting hypoglycaemia the diabetic subjects receiving conventional treatment on the day before the study injected their normal dose of short acting insulin before the evening meal and delayed the injection of intermediate acting insulin until 2100 .

Three components of energy expenditure were measured-namely, resting metabolic rate, the increase in metabolic rate in response to the infusion of noradrenaline, and the change in metabolic rate after ingesting a liquid test meal. The changes in metabolic rate after the meal and noradrenaline are referred to as thermic responses. Predicted resting metabolic rate was calculated from the Mayo Clinic table, ${ }^{9}$ which takes into account age, sex, and surface area.

The subjects were allowed 30 minutes to equilibrate to the thermoneutral environment and then the resting metabolic rate was measured over 20 minutes. The thermic responses to the meal and noradrenaline were measured on successive mornings after measurement of the resting metabolic rate. In the diabetic subjects during conventional treatment the resting metabolic rate and thermic response to infused noradrenaline were measured before the morning injection of short and intermediate acting insulin, whereas while receiving continuous subcutaneous insulin infusion the subjects maintained their usual basal rate of infusion of insulin during these measurements. For the measurement of the thermic response to a meal the diabetic subjects injected their normal morning conventional dosages of a short and intermediate acting insulin, or if receiving continuous subcutaneous insulin infusion injected a bolus of short acting insulin, after the measurement of the resting metabolic rate and exactly 20 mintues before ingesting the meal.

The thermic effect of the meal was assessed by measuring the rise in metabolic rate above resting during the two hours after the rapid ingestion of vanilla flavoured Carnation Build Up (Carnation Food Co, London) reconstituted with whole milk to give a final protein: fat:carbohydrate ratio of $1: 1 \cdot 2: 2 \cdot 3$ and energy content of $32 \cdot 6 \mathrm{~kJ} / \mathrm{kg}(7 \cdot 8 \mathrm{kcal} / \mathrm{kg})$ ideal body weight. This meal was designed to be similar in energy content and constituents to that which the diabetics would normally take each morning. As most subjects can tolerate only about three hours under the ventilated hood without discomfort, which would make readings unreliable, a liquid meal was chosen to facilitate the measurement of the thermic response within that time. Table I shows the total amount that each group received.

The thermic response to noradrenaline (Levophed) was measured as the rise in metabolic rate during a 45 minute infusion, which was administered intravenously at a rate of $0.1 \mu \mathrm{g} / \mathrm{kg}$ ideal body weight $/ \mathrm{min}$. Our previous work has shown that this infused dosage is the maximum that most can receive without stress and also achieves a plasma noradrenaline concentration of $5.9 \mathrm{nmol} / \mathrm{l}(1.0 \mathrm{ng} / \mathrm{ml}),{ }^{10}$ equivalent to that found in the plasma during moderate to severe exercise. Each group received a similar quantity of infused noradrenaline (table I).
Once the resting metabolic rate and the dynamic thermic responses had $\underline{\underline{T}}$ been measured in both non-diabetic and diabetic subjects we then assessed $z$ the effect of ingesting excess energy, mainly as fat, by supplementing their $\frac{\mathbb{Q}}{2}$ usual diet with $284 \mathrm{ml}$ fresh double cream daily for seven days. This is equivalent to an energy rise of $5.23 \mathrm{MJ}$ day $(1255 \mathrm{kcal} / \mathrm{day})$ and has a fat:protein:carbohydrate ratio of $24: 0 \cdot 7: 1 \cdot 0$. On the sixth and seventh days of this supplementation the tests of energy expenditure were repeated. The non-diabetic subjects underwent this protocol once, whereas the diabetic $\mathbb{\Phi}$ subjects were studied on two occasions-during conventional treatment and on attainment of optimal glycaemic control with continuous subcutaneous 2 insulin infusion (see fig 1).

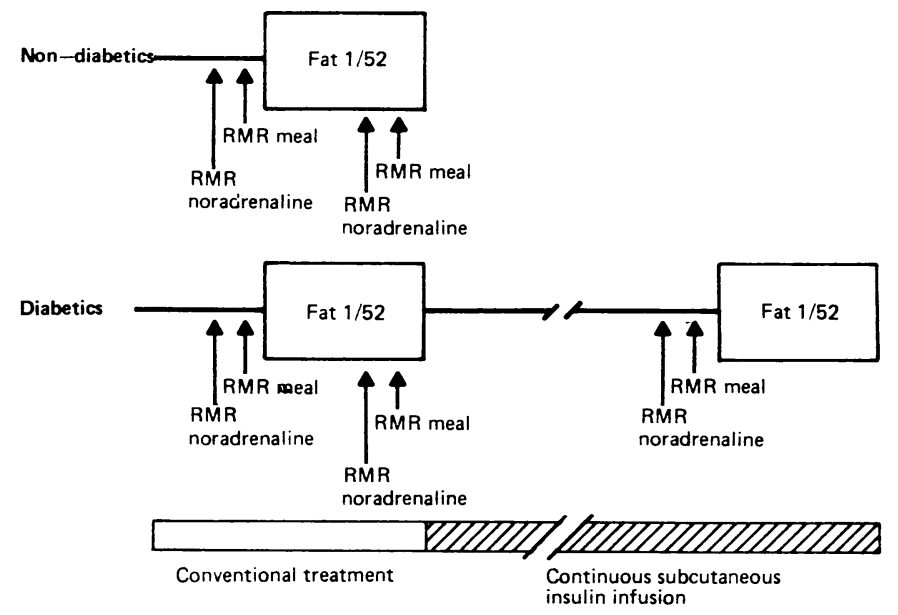

FIG 1 -Protocol. Resting metabolic rate $(\mathrm{RMR})$ and thermic responses to $Z$ noradrenaline and a meal measured before and on sixth and seventh days of fat supplementation during conventional treatment. This cycle of tests repeated in $\stackrel{\Phi}{3}$ diabetic subjects receiving continuous subcutaneous insulin infusion.

For venous blood sampling a 19 gauge cannula (Abbott) was inserted into a brachial vein and kept patent with a few $\mathrm{ml} 3 \cdot 8 \%(\mathrm{wt} / \mathrm{vol})$ sodium citrate $\mathrm{O}$ $(B P C)$. Noradrenaline was infused through a similar cannula placed in a brachial vein in the other arm. Venous blood samples were taken before and $\bar{\partial}$ at 30,60,90, and 120 minutes after the test meal and analysed for glucose. $ٌ$

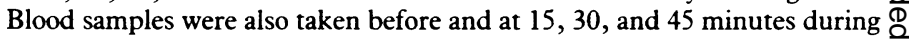
noradrenaline infusion and assayed for glucose, total free fatty acids, and $\underset{\vec{F}}{\vec{F}}$ glycerol.

Plasma glucose was assayed by an enzymatic colorimetric method adapted from Trinder, ${ }^{11}$ and glycerol by a fully enzymatic method using the $\mathrm{BCL}$ triglyceride kit (No 125032) with lipases and esterases removed and pyruvate kinase/lactate dehydrogenase (BCL No 109096) added separately. Total free fatty acids were measured by an extraction-photometric method according to the method of Chromy et al ${ }^{12}$ and haemoglobin $A_{1}$ by the stable $\mathrm{HbA}_{1}$ endosmotic method (Corning). ${ }^{13}$ Our range of $\mathrm{HbA}_{1}$ for a non-diabetic $\frac{\sigma}{3}$ population is $5 \cdot 0-7 \cdot 9 \%$.

To assess whether it was possible to improve the thermic response to noradrenaline infusion we studied the effect of metformin, which has been shown to reduce insulin resistance in insulin dependent diabetic patients. ${ }^{1+}$ 윽 Six of our diabetic subjects volunteered to take metformin $500 \mathrm{mg}$ three $\mathrm{N}$ times daily by mouth for 14 days while receiving continuous subcutaneous $\sigma$ insulin infusion. Only three managed to do this, however, the others $\frac{7}{0}$ developing nausea and abdominal upset necessitating withdrawal of the metformin. Each subject had his or her thermic response to noradrenaline $N$ infusion measured before and at the 14th day of metformin treatment.

\section{ETHICS AND STATISTICS}

Ethical approval for the study was given by the ethical committee of Tayside Health Board and fully informed consent obtained from each subject. Statistical analysis was by Student's paired $t$ test for the comparison $\frac{\vec{D}}{\mathbb{D}}$ of within group responses and by Student's unpaired $t$ test for comparing $\stackrel{\odot}{\rightarrow}$ diabetic and control responses. The accumulative incremental response was $\mathbb{D}$ calculated from the area under the response curve above basal. Results are expressed as mean and one standard error of the mean (SEM) (except for subject data in table $\mathrm{I}$, which are expressed as mean and standard deviation 0 $(\mathrm{SD})$ ). Ninety five per cent confidence intervals of estimated differences are also shown where appropriate. 


\section{Results}

The concentration of $\mathrm{HbA}_{1}$ decreased from $12 \cdot 1(0 \cdot 7) \%$ during conventional treatment to $7 \cdot 5(0 \cdot 2) \%$ during continuous subcutaneous insulin infusion $(p<0.001)$. Fasting plasma glucose also showed a significant decline (table II) but insulin dosages were not altered $(42 \cdot 8(3 \cdot 8) \mathrm{U} /$ day with conventional treatment $v 43 \cdot 6(4 \cdot 5) \mathrm{U} /$ day with continuous subcutaneous insulin infusion). The weight of the diabetic subjects rose from $67 \cdot 9(4 \cdot 2) \mathrm{kg}$ to $71 \cdot 4(5 \cdot 1) \mathrm{kg}(\mathrm{p}<0 \cdot 05)$ over the study period.

Resting metabolic rate-The poorly controlled diabetic subjects had an increased resting metabolic rate compared with predicted values (table III). or continuous subcutaneous insulin infusion (table IV; fig 2). The thermic response to the meal in the non-diabetic subjects was unaltered by fat supplementation. This was in contrast with the diabetic group receiving conventional treatment, who when given the fat supplement showed a significant reduction of their thermic response during the second hour $(p<0.05)$, which was $57 \%$ less than that observed in the same subjects before fat supplementation (mean difference $23.2 \mathrm{~kJ}(5.5 \mathrm{kcal}) ; 95 \%$ confidence interval 0.25 to $46.15 \mathrm{~kJ}(0.06$ to $11.03 \mathrm{kcal}))$. When these same subjects had attained optimal glycaemic control they then showed no significant reduction in their thermic response to the meal during fat supplementation.

Thermic response to noradrenaline-There was an increase in energy

TABLE II-Plasma glucose responses to meal before and during fat supplementation. Values are means (SEM in parentheses)

\begin{tabular}{|c|c|c|c|c|}
\hline \multirow[b]{2}{*}{ Study group } & \multicolumn{2}{|c|}{ Basal glucose (mmol l) } & \multicolumn{2}{|c|}{ Accumulative incremental glucose rise (mmol.min) } \\
\hline & Usual intake & Fat supplemented & Usual intake & Fat supplemented \\
\hline $\begin{array}{l}\text { Non-diabetics } \\
\text { Diabetics having conventional treatment } \\
\text { Diabetics receiving continuous subcutaneous insulin infusion }\end{array}$ & $\begin{array}{l}5.65(0.24) \\
11.60(0.95) \\
7.06(1.60) \mathrm{tt \dagger}\end{array}$ & 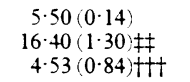 & $\begin{array}{l}77 \cdot 1(30 \cdot 1) \\
427 \cdot 3(79 \cdot 7)^{\star \star \star} \\
387 \cdot 0(789 \cdot 8) \star \star\end{array}$ & $\begin{array}{l}57 \cdot 32(33 \cdot 6) \\
235 \cdot 1(95 \cdot 4) \\
403 \cdot 7(59 \cdot 6)^{\star \star}\end{array}$ \\
\hline
\end{tabular}

Diabetics having conventional treatment or continuous subcutaneous insulin infusion $v$ non-diabetics: ${ }^{\star \star} p<0 \cdot 02, \star \star \star p<0 \cdot 01$.

Diabetics receiving continuous subcutaneous insulin infusion $v$ diabetics having conventional treatment: $t \dagger p<0.01$.

Diabetics having conventional treatment - Fat supplemented $v$ usual intake: $\ddagger \neq p<0 \cdot 02$.

Conversion: SI to traditional units-Glucose: $1 \mathrm{mmol} l \approx 18 \mathrm{mg} / 100 \mathrm{ml}$.

TABLE III-Predicted and observed values for resting metabolic rate $(\mathrm{kf} / \mathrm{min})$. Values are means (SEM in parentheses)

\begin{tabular}{lccc}
\hline & & \multicolumn{2}{c}{ Observed } \\
\cline { 3 - 4 } Study group & Predicted & Usual intake & Fat supplemented \\
\hline $\begin{array}{l}\text { Non-diabetics } \\
\text { Diabetics having conventional } \\
\text { treatment }\end{array}$ & $4.37(0.13)$ & $4 \cdot 24(0.12)$ & $4.25(0.19)$ \\
$\begin{array}{l}\text { Diabetics receiving continuous } \\
\text { subcutaneous insulin infusion }\end{array}$ & $4.69(0.26)$ & $4.93(0.27) \dagger$ & $4.86(0.24)$ \\
\hline
\end{tabular}

Diabetics having conventional treatment-observed on usual intake $v$ predicted: $\nmid p<0.05$. Diabetics receiving usual intake: continuous subcutaneous insulin infusion $v$ conventional treatment: ${ }^{\star \star} p<0 \cdot 02$.

Conversion: $S I$ to traditional units-Energy: $1 \mathrm{~kJ} \approx 0.24 \mathrm{kcal}$ expenditure during noradrenaline infusion in all the subjects. Seven of the eight diabetic subjects showed a blunted response to infused noradrenaline compared with our non-diabetic subjects (table IV; fig 3). One diabetic subject had to be excluded, however, because the noradrenaline infusion produced a severe adverse reaction making accurate measurements impossible. She was aged 26 , was of normal weight $(64.5 \mathrm{~kg})$, and did not differ from the others in duration of diabetes (six years), $\mathrm{HbA}_{1}$ value $(7.9 \%)$, or insulin dosage ( $58 \mathrm{U} /$ day). The incremental thermic rise shown by the other seven diabetic subjects during conventional treatment was $59 \%$ lower than that shown by the non-diabetic group (mean difference $16 \mathrm{~kJ}$ ( $3.8 \mathrm{kcal}) ; 95 \%$ confidence interval $4 \cdot 7$ to $27 \cdot 3 \mathrm{~kJ}(1 \cdot 1$ to $6 \cdot 5 \mathrm{kcal})$ ). The thermic response did not improve significantly with precise glycaemic control, however, and remained $51 \%$ lower than that shown by the non-diabetic group (mean difference $13.7 \mathrm{~kJ}$ ( $3.3 \mathrm{kcal}) ; 95 \%$ confidence interval 2.9 to $24.5 \mathrm{~kJ}(0.7$ to $5.9 \mathrm{kcal})$ ). When repeated during fat supplementation no significant

TABLE IV-Accumulative incremental metabolic response to test meal and noradrenaline infusion before and during fat supplementation. Values are means (SEM in parentheses)

\begin{tabular}{|c|c|c|c|c|c|}
\hline \multirow[b]{2}{*}{ Study group } & & \multicolumn{3}{|c|}{ Response to test meal $(\mathrm{kJ}) \ddagger$} & \multirow{2}{*}{$\begin{array}{c}\text { Response to } \\
\text { noradrenaline } \\
\text { infusion (total kJ) }\end{array}$} \\
\hline & & Total & lst Hour & 2nd Hour & \\
\hline Non-diabetics & $\left\{\begin{array}{l}\text { Usual intake } \\
\text { Fat supplement }\end{array}\right.$ & $\begin{array}{l}72 \cdot 2(8 \cdot 4) \\
78 \cdot 0(9 \cdot 4)\end{array}$ & $\begin{array}{l}34.6(3 \cdot 4) \\
37 \cdot 6(6 \cdot 4)\end{array}$ & $\begin{array}{l}37 \cdot 5(5 \cdot 3) \\
40 \cdot 4(11 \cdot 2)\end{array}$ & $\begin{array}{l}27 \cdot 1(3 \cdot 4) \\
20 \cdot 6(3 \cdot 9)\end{array}$ \\
\hline Diabetics having conventional treatment & $\left\{\begin{array}{l}\text { Usual intake } \\
\text { Fat supplement }\end{array}\right.$ & $\begin{array}{l}73 \cdot 6(12 \cdot 3) \\
44 \cdot 8(14 \cdot 0)\end{array}$ & $\begin{array}{l}33 \cdot 1(5 \cdot 7) \\
27 \cdot 5(9 \cdot 1)\end{array}$ & $\begin{array}{l}40 \cdot 5(7 \cdot 1) \\
17 \cdot 3(6 \cdot 3) \dagger\end{array}$ & $\begin{array}{c}11 \cdot 1(3 \cdot 7)^{\star \star \star} \\
8 \cdot 4(2 \cdot 8)^{\star}\end{array}$ \\
\hline Diabetics receiving continuous subcutaneous insulin infusion & $\left\{\begin{array}{l}\text { Usual intake } \\
\text { Fat supplement }\end{array}\right.$ & $\begin{array}{l}71 \cdot 0(14 \cdot 6) \\
71 \cdot 0(9 \cdot 9)\end{array}$ & $\begin{array}{l}33 \cdot 9(6 \cdot 3) \\
32 \cdot 5(4 \cdot 6)\end{array}$ & $\begin{array}{l}37 \cdot 1(9 \cdot 9) \\
38 \cdot 5(5 \cdot 9)\end{array}$ & $\begin{array}{l}13 \cdot 4(3 \cdot 7)^{\star \star} \\
16 \cdot 1(1 \cdot 9)\end{array}$ \\
\hline
\end{tabular}

$\ddagger$ Test meal responses compared in eight diabetic and eight non-diabetic subjects.

@Noradrenergic responses compared in seven diabetic and eight non-diabetic subjects.

Diabetics having conventional treatment or continuous subcutaneous insulin infusion $v$ non-diabetics (comparing usual diet $v$ usual diet; fat supplement

$v$ fat supplement): ${ }^{*} \mathrm{p}<0.05,{ }^{\star \star} \mathrm{p}<0.02,{ }^{\star \star \star} \mathrm{p}<0.01$

$v$ fat supplement): $" \mathrm{p}<0.05, \star \mathrm{p}<0.02, \star \star \star \mathrm{p}<0.01$.
Diabetics having conventional treatment - Fat supplement $v$ usual diet: $\mathrm{t} \mathrm{p}<0.05$

Conversion: SI to traditional units-Energy: $1 \mathrm{~kJ} \approx 0 \cdot 24 \mathrm{kcal}$.

The estimated difference was $345.6 \mathrm{~kJ}(82.6 \mathrm{kcal})$ per 24 hours with $95 \%$ confidence limits of 18.7 and $672.5 \mathrm{~kJ}(4.5$ and $160.7 \mathrm{kcal})$. The resting metabolic rate decreased to within the predicted range with continuous subcutaneous insulin infusion. The decrease with precise glycaemic control reduced energy expenditure by an estimated $374.4 \mathrm{~kJ}(89.5 \mathrm{kcal})$ per 24 hours $(95 \%$ confidence limits 93.6 and $655 \cdot 2 \mathrm{~kJ}(22 \cdot 4$ and $156 \cdot 6 \mathrm{kcal}))$. The non-diabetic subjects showed a good correlation between observed and predicted values $(r=0.93)$. There was no significant change in the resting metabolic rate with fat supplementation in either the non-diabetic subjects or the diabetic subjects during conventional treatment or continuous subcutaneous insulin infusion.

Thermic response to meal-The thermic response to the meal was similar in non-diabetic and diabetic subjects whether receiving conventional treatment alteration in response was seen in any of the groups. The thermic responses to both noradrenaline and a meal in those subjects with detectable $C$ peptide were similar to those with no evidence of endogenous insulin secretion.

Effect of metformin-Metformin improved the thermic response to noradrenaline infusion in the three subjects studied. The accumulative incremental energy rise to noradrenaline for the three subjects receiving continuous subcutaneous insulin infusion alone was $14 \cdot 9,5 \cdot 2$, and $6 \cdot 3 \mathrm{~kJ}$ $(3 \cdot 6,1 \cdot 2$, and $1 \cdot 5 \mathrm{kcal})$ and with the addition of metformin $23 \cdot 0,11 \cdot 4$, and $19 \cdot 5 \mathrm{~kJ}(5 \cdot 5,2 \cdot 7$, and $4 \cdot 7 \mathrm{kcal})$ respectively.

Glucose response to meal -The accumulative incremental rise of glucose in response to the meal (table II) was 5.5-fold higher in the diabetic subjects taking conventional treatment as compared with the non-diabetic group. With precise glycaemic control this figure still remained fivefold greater than 
TABLE V-Biochemical response to noradrenaline infusion. Values are means (SEM in parentheses)

\begin{tabular}{|c|c|c|c|c|c|c|c|}
\hline \multirow[b]{2}{*}{ Study group } & \multirow[b]{2}{*}{ Intake } & \multicolumn{2}{|c|}{ Free fatty acids } & \multicolumn{2}{|c|}{ Glycerol } & \multicolumn{2}{|c|}{ Glucose } \\
\hline & & $\underset{(\mathrm{mmolil})}{\text { Basal }}$ & $\begin{array}{c}\text { Rise } \\
\text { (mmol.min) }\end{array}$ & $\underset{(\mathrm{mmol} / \mathrm{l})}{\text { Basal }}$ & $\begin{array}{c}\text { Rise } \\
(\mathrm{mmol} \cdot \mathrm{min})\end{array}$ & $\begin{array}{l}\text { Basal } \\
(\mathrm{mmol} / \mathrm{l})\end{array}$ & $\begin{array}{c}\text { Rise } \\
(\mathrm{mmol} \cdot \mathrm{min})\end{array}$ \\
\hline Non-diabetics $(\mathrm{n}=8$ ) & $\left\{\begin{array}{l}\text { Usual intake } \\
\text { Fat supplement }\end{array}\right.$ & $\begin{array}{l}0.381(0.036) \\
0.449(0.046)\end{array}$ & $\begin{array}{l}23 \cdot 1(2 \cdot 3) \\
20 \cdot 8(1 \cdot 4)\end{array}$ & $\begin{array}{l}0.133(0.045) \\
0.155(0.082)\end{array}$ & $\begin{array}{l}4.64(0.34) \\
5.51(0.22)\end{array}$ & $\begin{array}{l}5.5(0.1) \\
5.6(0.1)\end{array}$ & $\begin{array}{l}43 \cdot 1(6 \cdot 0) \\
30 \cdot 9(4 \cdot 7)\end{array}$ \\
\hline Diabetics having conventional treatment $(n=7)$ & $\begin{array}{l}\text { Usual intake } \\
\text { Fat supplement }\end{array}$ & $\begin{array}{l}0.544(0.061) \\
0.477(0.041)\end{array}$ & $\begin{array}{l}26 \cdot 8(2 \cdot 8) \\
23 \cdot 1(2 \cdot 9)\end{array}$ & $\begin{array}{l}0.276(0.039)^{\star \star \star} \\
0.344(0.073)^{\star}\end{array}$ & $\begin{array}{l}5.35(0.64) \\
7.23(1.6)\end{array}$ & $\begin{array}{l}14 \cdot 1(1 \cdot 6)^{\star \star \star \star} \\
13.6(1 \cdot 6)^{\star}\end{array}$ & $\begin{array}{l}51 \cdot 3(7 \cdot 2) \\
40 \cdot 9(15 \cdot 0)\end{array}$ \\
\hline Diabetics receiving continuous subcutaneous insulin infusion $(n=7)$ & $\left\{\begin{array}{l}\text { Usual intake } \\
\text { Fat supplement }\end{array}\right.$ & $\begin{array}{l}0.408(0.074) \\
0.452(0.067)\end{array}$ & $\begin{array}{l}20 \cdot 2(1 \cdot 7) \\
20 \cdot 5(2 \cdot 1)\end{array}$ & $\begin{array}{l}0.210(0.067) \\
0.267(0.085)\end{array}$ & $\begin{array}{l}5 \cdot 10(1.09) \\
3.35(0.65)\end{array}$ & $\begin{array}{l}6 \cdot 3(1 \cdot 2)+t+ \\
7 \cdot 5(1 \cdot 6)+t \ddagger\end{array}$ & $\begin{array}{l}17 \cdot 8(14 \cdot 7) \dagger \\
20 \cdot 9(7 \cdot 1)\end{array}$ \\
\hline
\end{tabular}

Diabetics having conventional treatment or continuous subcutaneous insulin infusion $v$ non-diabetics (comparing usual intake $v$ usual intake; fat supplement $v$ fat supplement): ${ }^{\star} \mathrm{p}<0 \cdot 05$, $\star \star x<0.01, \star \star \star \star x<0.001$

Diabetics receiving continuous subcutaneous insulin infusion and usual intake $v$ diabetics receiving conventional treatment and usual intake: $\nmid \mathrm{p}<0.05, \mathrm{t \dagger}+\mathrm{p}<0.01$.

Diabetics receiving continuous subcutaneous insulin infusion and fat supplement $z^{\prime}$ diabetics receiving conventional treatment and fat supplement: $\neq \pm \neq p<0 \cdot 01$.

Conversion: SI to traditional units - Free fatty acids: $1 \mathrm{mmol} / \approx 25 \cdot 6 \mathrm{mg} / 100 \mathrm{ml}$. Glycerol: $1 \mathrm{mmol} / 2 \approx 9 \cdot 2 \mathrm{mg} / 100 \mathrm{ml}$. Glucose $1 \mathrm{mmol} / 1 \approx 18 \mathrm{mg} / 100 \mathrm{ml}$.
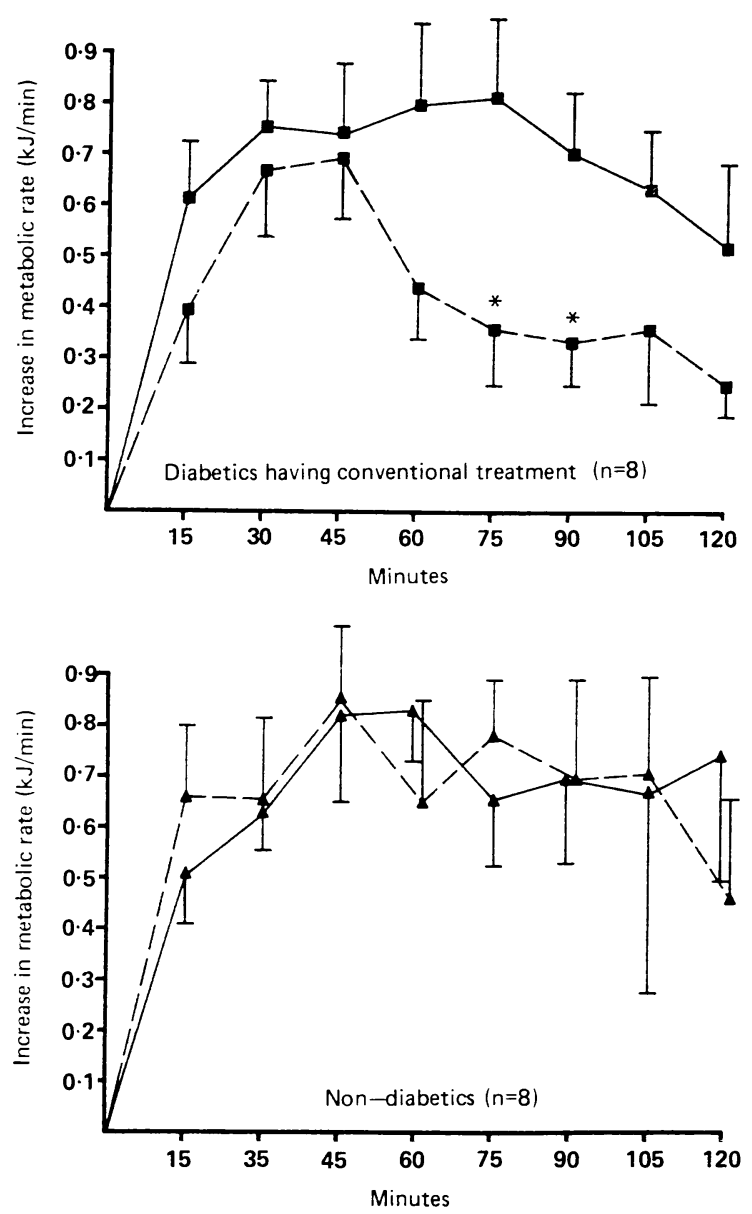

in the non-diabetic group, though the thermic responses were similar. No significant changes were found in the accumulative incremental glucose response to the meal during fat supplementation.

Biochemical response to noradrenaline-The significantly higher fasting plasma glycerol concentration in those taking conventional treatment compared with the non-diabetic subjects suggested a higher basal lipolytic rate in these diabetic subjects (table V). Nevertheless, the accumulative incremental rises of glycerol and free fatty acids were similar in all three groups, suggesting similar increases in lipolysis in response to noradrenaline despite pronounced differences in thermic responsiveness.

\section{Discussion}

Quantitatively the resting metabolic rate accounts for $65 \%$ to $75 \%$ of man's total 24 hour energy expenditure. ${ }^{15}$ Hence relatively small changes in the resting metabolic rate have a substantial accumulative effect on long term energy balance. We calculate from the present

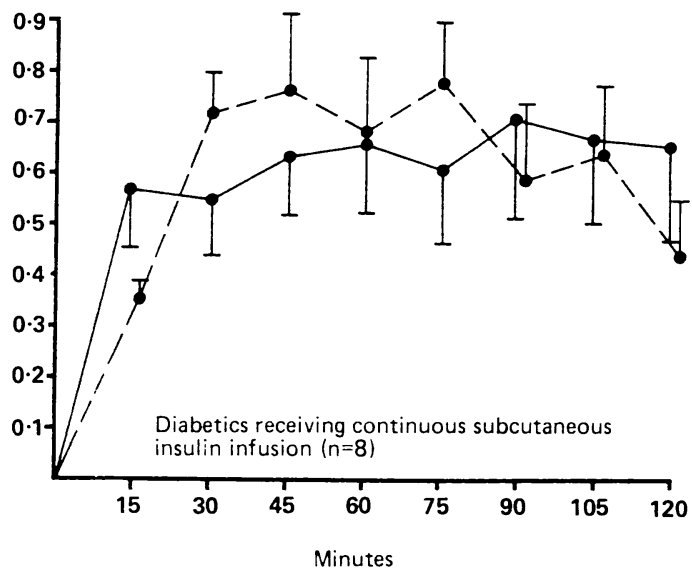

FIG 2-Mean thermic responses to meal before $(-)$ and during (- - ) fat supplementation. Bars are SEM ${ }^{\star} \mathrm{p}<0.05$.

Conversion: SI to traditional units-Energy: $1 \mathrm{~kJ} \approx 0.24 \mathrm{kcal}$. 


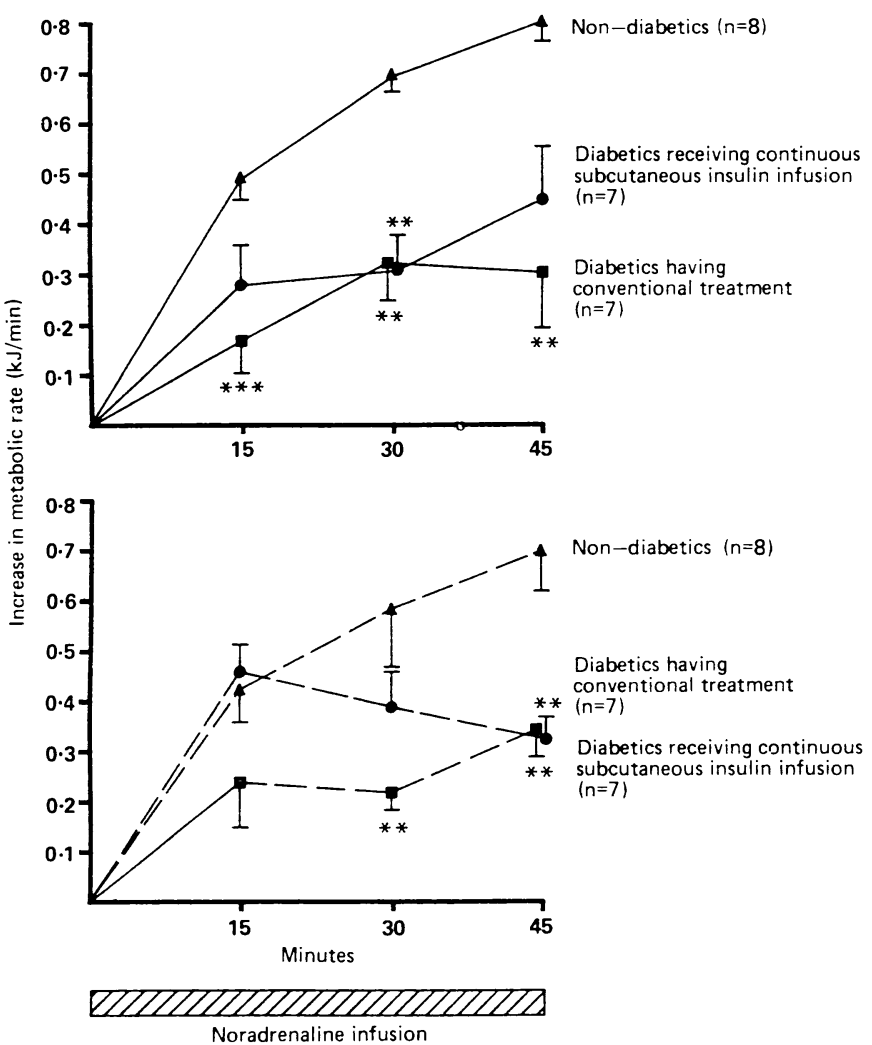

FIG 3-Mean thermic responses to noradrenaline infusion before (- $\longrightarrow$ ) and during (- - ) fat supplementation in eight non-diabetics and seven diabetics during conventional treatment and during continuous subcutaneous insulin infusion. Bars are SEM. Diabetics $v$ non-diabetics: ${ }^{\star \star} p<0.02,{ }^{\star \star \star} p<0.01$.

Conversion: SI to traditional units-Energy: $1 \mathrm{~kJ} \approx 0 \cdot 24 \mathrm{kcal}$.

responsible for this increase in the metabolic rate remain unclear but may be related to increased protein flux ${ }^{17}$ and also enhanced fat lipolysis and oxidation, as suggested by the raised plasma glycerol concentrations in our diabetic subjects poorly controlled with conventional treatment.

The thermic effect of food makes an important contribution to the remaining $25-35 \%$ of total 24 hour energy expenditure. Golay $e t$ al reported a blunted thermic response to oral glucose in type II obese diabetic subjects who had similar fasting glucose concentrations to our subjects taking conventional treatment. ${ }^{3} \mathrm{We}$, however, were not able to show any reduction in the thermic response to a more physiological meal while our diabetic subjects were taking their usual diabetic diet whether glycaemic control was poor or precise. The lack of obesity, mixed constituent ingredients of the meal, and type I nature of our diabetic subjects may account for this difference.

Our diabetic subjects, nevertheless, did show a reduction in their thermic response to the meal during fat supplementation which could be rectified by optimal glycaemic control. Though the reduction amounted to a diminution of energy expenditure in the region of only $23 \mathrm{~kJ}(5.5 \mathrm{kcal})$ over two hours, postprandial thermogenesis may continue for up to nine hours, and therefore the energy deficit might have been appreciably greater had we measured expenditure of three main meals and assorted snacks over 24 hours using direct calorimetry. Hence adequate insulin repletion is important to maintain the usual thermic response to the meal when the subject overfeeds. This also emphasises the value of the British Diabetic Association's recommendation for a reduction of fat in the diet of diabetic patients.

We were not able to show a significant increase in the resting metabolic rate or in the thermic response to the meal or to noradrenaline infusion with fat supplementation in either our diabetic or non-diabetic subjects. The concept of luxus consumption, also known as overfeeding (non-shivering) thermogenesis, has never been shown conclusively in man. ${ }^{18}$ Nevertheless, overfeeding can increase energy expenditure. In a recent study of six subjects overfed an extra $6.2 \mathrm{MJ}(1482 \mathrm{kcal})$ daily for 42 days the resting metabolic rate increased by $12 \% .{ }^{19} \mathrm{~A}$ small rise $(5.6 \%)$ in 24 hour energy expenditure has also been reported in lean man using direct calorimetry after one week of overfeeding fat designed to increase energy intake by $50 \% .{ }^{20}$ In this latter study the resting metabolic rate increased by $2.8 \%(0.14 \mathrm{~kJ}(0.03 \mathrm{kcal}) / \mathrm{min})$, somewhat similar to the mean rise of $3 \%$ seen in our diabetic subjects during continuous subcutaneous insulin infusion when overfed fat, though the rise in metabolic rate in our study failed to reach statistical significance. The reported increases in energy expenditure may not necessarily represent any enhancement of non-shivering thermogenesis, for a small increase in lean mass with altered substrate flux energetics could account for much if not all of the altered energy expenditure. "The lack of change in the thermic response to noradrenaline infusion suggests that non-shivering thermogenesis had not been increased in our subjects by one week of fat supplementation. Our findings emphasise, however, that both nondiabetic and diabetic subjects cannot quickly compensate for a rise in energy intake by a rapid increase in energy expenditure.

Noradrenaline is increased in many physiological settings and hence makes some contribution to the remaining total 24 hour energy expenditure. The mean thermic response of infused noradrenaline in our diabetic subjects was reduced by $59 \%$ and did not improve appreciably with tight glycaemic control. This would have the effect of limiting energy expenditure and may be one more factor predisposing to weight gain. It appears that our diabetic subjects did not compensate for an apparent energy excess brought about by the reduction in the resting metabolic rate with precise glycaemic control by an increase in noradrenergic or dietary induced thermic responses.

What is the mechanism responsible for the blunted thermic response to noradrenaline? Though brown fat is found in adults, our work suggests that its energetic value is small and could not account for the blunted thermic response to noradrenaline infusion. ${ }^{21}$ The work of Astrup et al ${ }^{22}$ suggests that most of the heat generated by catecholamines in man actually comes from muscle, possibly related to fat oxidation. ${ }^{23}$ We did, however, find an increase in the blunted thermic response to infused noradrenaline with the addition of metformin to continuous subcutaneous insulin infusion. Metformin has been shown to reduce insulin resistance in insulin dependent diabetic subjects. ${ }^{14}$ Also continuous subcutaneous insulin infusion improves but does not necessarily correct the insulin resistance of type I diabetes mellitus. ${ }^{24}$ Though we did not measure insulin resistance during treatment with metformin in our subjects and so can only conjecture the reason for the thermic improvement with this drug, we speculate whether a change in insulin sensitivity might be implicated. If so then this would suggest that the persistence of a blunted noradrenergic response during continuous subcutaneous insulin infusion is associated to some degree, directly or indirectly, with the continuation of insulin resistance. The fact that metformin can improve the reduced noradrenergic thermic response in type I diabetes gives some credence to the past practice of administering biguanide to obese subjects poorly controlled by insulin. ${ }^{25}$

A blunted catecholamine thermic response has also been reported in other nutritional states such as lactation, ${ }^{26}$ in some obese women and women with a history of obesity, ${ }^{10}$ and in some subjects of normal weight who have never been obese but have to maintain a low energy intake to prevent weight gain. ${ }^{27}$ This thermic response may also be reduced by prolonged chronic nutritional deprivation ${ }^{28}$ and increased by chronic ephedrine administration. ${ }^{29}$ The exact mechanism responsible in each setting is still unresolved but probably more than just insulin is concerned. This might also have been the case in our type I diabetic subjects, for metformin improved but did not correct completely the blunted thermic noradrenergic response.

In conclusion it appears that adequate glycaemic control with continuous subcutaneous insulin infusion does not correct all the metabolic abnormalities of diabetes mellitus. Possibly other agents will be required to achieve this aim. Diabetic patients seem to be at a disadvantage regarding energy balance when glycaemic control is improved. In this setting the resting metabolic rate decreases 
appreciably and if a reduction in intake is not advised then weight increase is likely, for diabetic patients do not appear to compensate by an increase in the thermic response to a meal and noradrenaline stimulation. It is therefore interesting that after a mean of 5.3 months of continuous subcutaneous insulin infusion our subjects gained an average of $3 \cdot 5 \mathrm{~kg}$.

We thank all our volunteers, Dr Iain Crombie and Mr Simon Ogston for statistical advice, Ms Maureen Hughes and Miss Shirley Dryden for expert typing, and Dr A McCuish (Glasgow Royal Infirmary) for measuring C peptide values. We also thank the MRC Dunn Nutrition Unit, Cambridge, and $\mathrm{Mr}$ R Rimmer and his colleagues at Ninewells Hospital for advice and help with calorimeter construction. The project was supported by a gran from the Scottish Home and Health Department, which also supported PL, and also from Nordisk UK. PI was supported by a grant from Birthright. A grant from Tenovus, Scotland, provided most of the continuous subcutaneous insulin infusion pumps used in this project, while maintenance of these pumps was aided by some cannulas and syringes from Travenol and a grant from the Tayside Health Board's research committee.

\section{References}

1 Rothwell NJ, Stock MJ. A role for insulin in the diet-induced thermogenesis of cafeteria fed rats. Metabolism 1981;30:673-8.

2 Felig P. Hypothesis; insulin is the mediator of feeding-related thermogenesis; insulin resistance and/or deficiency results in thermogenic defect which contributes to the pathogenesis of obesity. and/or deficiency results in ther

3 Golay A, Schutz Y, Mever HU, et al. Glucose induced thermogenesis in nondiabetic and diabetic obese subjects. Diabetes 1982;31:1023-8.

4 Ravussin E, Acheson KJ, Vernet $O$, Danforth E, Jequier E. Absence of a thermogenic defect in response to glucose/insulin infusion in human obesity and type II diabetics. In: Garrow JS Halliday D, eds. Substrate and energy metabolism in man. London: Libbey, 1985:A19.

5 Home PD, Capaldo B, Burrin JM, Worth R, Alberti KGMM. A crossover comparison of continuous subcutaneous insulin infusion (CSII) against multiple injections in insulindependent diabetic subjects. Improved control with CSII. Diabetes Care 1982;5:457-65.

6 Royal College of Physicians of London. Obesity. F R Coll Physicians Lond 1983;17:4-6.

7 Metropolitan Life Insurance Company. Morbidity among overweight men and women. Statistical Bulletin 1980;41(Feb):6.
8 Weir JBD. New methods for calculating metabolic rate with special reference to protein metabolism. 7 Physiol (Lond) 1949;109:1-9.

Co

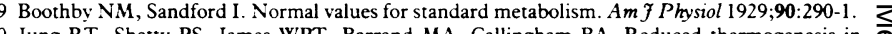
Jung RT, Shetty PS, James WPT, Barrand MA, Callingham BA. Reduced thermogenesis in obesity. Nature 1979;279:322-3.

11 Trinder $P$. Determination of blood glucose using an oxidase-peroxidase system with a non- $C$ carcinogenic chromogen. $f$ Clin Pathol 1969;23:158-6

12 Chromy N, Bergel J, Voznicek J, Kromholzova L, Musil J. Assay of serum free fatty acids by extraction photometric procedure. Clin Chim Acta 1977;80:327-32.

13 Menard LA, Dempsey ME, Blankstem LA, Aleyassine H, Wachs M, Soeldner JS. Quantitative J determination of glycosylated hemoglobin $A_{1}$ by agar gel electrophoresis. Clin Chem 1980;26: 1598-1603.

14 Gin H, Messerchmitt C, Brother E, Aubertin J. Metformin improved insulin resistance in type I insulin-dependent diabetic patients. Metabolism 1985;34:923-5.

15 Jequier E. Energy expenditure in obesity. Clin Endocrinol Metab 1984;13:563-80.

16 Nair KS, Halliday D, Garrow JS. Increased energy expenditure in poorly controlled type I (insulin 1984;27:13-6.

17 Nair KS, Garrow JS, Ford C, Mahler RF, Halliday D. Effect of poor diabetic control and obesity on whole body protein metabolism in man. Diabetologia 1983;25::400-3.

18 Welle S, Campbell RG. Stimulation of thermogenesis by carbohydrate overfeeding. 7 Clin Invest 1983;71:916-25.

19 Norgan NG, Durnin JVGA. The effect of 6 weeks of overfeeding on the body weight, body composition and energy metabolism of young men. Am f Clin Nutr 1980;33:978-88.

20 Dallosso HM, James WPT. Whole body calorimetry studies in adult man. Effect of fat overfeeding on $24 \mathrm{hr}$ energy expenditure. Br $\mathcal{F}$ Nutr 1984;52:49-64.

21 Cunningham S, Leslie $\mathrm{P}$, Hopwood D, et al. The characterisation and energetic potential of brown adipose tissue in man. Clin Sci 1915;69:343-8.

22 Astrup A, Bulow J, Madsen J, Christensen NJ. Contribution of BAT and skeletal muscle to thermogenesis induced by ephedrine in man. Am f Physiol 1985;248:E507-15.

23 Havel RJ, Carlson LA, Ekelurd L-G, Holmgren A. Studies on the relation between mobilisation of free fatty acids and energy metabolism in man; effects of norepinephrine and nicotinic acid. Metabolism 1964;13:1402-11.

24 Simonson DC, Tamborlane WV, Sherwin RS, Smith JD, DeFronzo RA. Improved insulin sensitivity in patients with type I diabetes mellitus after CSII. Diabetes 1985:34(suppl 3):80-6. 1962;16:129-32.

26 Illingworth PJ, Jung RT, Howie PW, Leslie P, Isles TE. A diminution in energy expenditure $\mathrm{C}$ during lactation. Br Med f 1986;292:437-41.

27 Morgan JB, York DA, Wasilewska A, Portman J. A study of the thermic responses to a meal and to a sympathomimetic drug (ephedrine) in relation to energy balance in man. Brf Nutr 1982;47: $\mathrm{N}$ 21-32.

28 Finer N, Swan PC, Mitchell FT. Suppression of norepinephrine-induced thermogenesis in $\mathrm{O}$ human obesity by diet and weight loss. Int $\mathcal{F}$ Obes 1985;9:121-6.

29 Astrup A, Lundsgaard C, Madsen J, Christensen NJ. Enhanced thermogenic responsiveness during chronic ephedrine treatment in man. Am f Clin Nutr 1985;42:83-94.

Accepted 20 August 1986

\title{
Detection of spread of malignant lymphoma to the liver by low field strength magnetic resonance imaging
}

\author{
M A RICHARDS, J A W WEBB, \\ R H REZNEK, \\ G DAVIES, \\ S E JEWELL, \\ W S SHAND, \\ P F M WRIGLEY, T A LISTER
}

\begin{abstract}
The accuracy of spin lattice relaxation time $\left(T_{1}\right)$ measurement obtained with a low field strength magnetic resonance imager for the detection of spread of malignant lymphoma to the liver was assessed. The results of histological examination obtained at open liver biopsy were compared with liver $T_{1}$ values in 27 patients with lymphoma. The normal range for $T_{1}$ was estab-
\end{abstract}

St Bartholomew's Hospital, London EC1A

M A RICHARDS, MB, MRCP, Imperial Cancer Research Fund department of medical oncology

J A W WEBB, MD, FRCR, department of radiology

R H REZNEK, MRCP, FRCR, department of radiology

G DAVIES, MS, FRCS, department of surgery

S E JEWELL, HDCR (R), department of radiology

W S SHAND, MD, FRCS, department of surgery

P F M WRIGLEY, PHD, FRCP, Imperial Cancer Research Fund department of medical oncology

T A LISTER, MD, FRCP, Imperial Cancer Research Fund department of medical oncology

Correspondence to: Dr Lister. lished by scanning 61 healthy volunteers. Magnetic resonance imaging was highly sensitive in detecting hepatic lymphoma, all seven patients with liver lymphoma proved by biopsy having considerably higher $T_{1}$ values. Specificity was less good. Five out of 20 patients with no histological evidence of hepatic lymphoma had abnormal $T_{1}$ values.

This level of sensitivity is considerably better than that $\mathscr{N}$ reported for other imaging methods and contrasts with the results of one previous study using a different magnetic resonance system. Low field strength magnetic resonance imaging may $\tilde{N}$ prove to be a useful screening test in patients with lymphoma. The presence of a normal liver $T_{1}$ seems to be a reliable guide to the absence of hepatic disease.

\section{Introduction}

Accurate diagnosis of spread of disease to the liver in patients with malignant lymphoma is important for selecting treatment and $\stackrel{\mathbb{Q}}{\varrho}$ determining prognosis. Clinical assessment of liver disease is notoriously inaccurate; hepatomegaly is an unreliable guide to the presence of lymphoma, ${ }^{12}$ raised serum alkaline phosphatase activities may be found when the results of liver biopsies are normal, ${ }^{2}$

\section{(1)} . 